\title{
Ketone- and Cyano-Selenoesters to Overcome Efflux Pump, Quorum-Sensing, and Biofilm-Mediated Resistance
}

\author{
Nikoletta Szemerédi ${ }^{1}{ }^{\circledR}$, Annamária Kincses ${ }^{1}{ }^{\oplus}$, Katerina Rehorova ${ }^{2}{ }^{\oplus}$, Lan Hoang ${ }^{2}$, \\ Noemi Salardón-Jiménez ${ }^{3}$, Clotilde Sevilla-Hernández ${ }^{3}{ }^{\circledR}$, Jitka Viktorová ${ }^{2}$, \\ Enrique Domínguez-Álvarez ${ }^{3, *}$ and Gabriella Spengler $1, * \mathbb{B}$
}

1 Department of Medical Microbiology and Immunobiology, Faculty of Medicine, University of Szeged, Dóm tér 10, 6720 Szeged, Hungary; szemeredi.nikoletta@med.u-szeged.hu (N.S.);

kincses.annamaria90@gmail.com (A.K.)

2 Department of Biochemistry and Microbiology, Faculty of Food and Biochemical Technology, University of Chemistry and Technology Prague, Technická 3, 16628 Prague, Czech Republic; katerina.rehorova@vscht.cz (K.R.); hoang1@vscht.cz (L.H.); jitka.prokesova@vscht.cz (J.V.)

3 Instituto de Química Orgánica General (IQOG-CSIC), Consejo Superior de Investigaciones Científicas, Juan de la Cierva 3, 28006 Madrid, Spain; noemi.sj.95@gmail.com (N.S.-J.); clo.sh.1995@gmail.com (C.S.-H.)

* Correspondence: e.dominguez-alvarez@iqog.csic.es (E.D.-Á.); spengler.gabriella@med.u-szeged.hu (G.S.)

Received: 12 November 2020; Accepted: 10 December 2020; Published: 11 December 2020

\begin{abstract}
The emergence of drug-resistant pathogens leads to a gradual decline in the efficacy of many antibacterial agents, which poses a serious problem for proper therapy. Multidrug resistance (MDR) mechanisms allow resistant bacteria to have limited uptake of drugs, modification of their target molecules, drug inactivation, or release of the drug into the extracellular space by efflux pumps (EPs). In previous studies, selenoesters have proved to be promising derivatives with a noteworthy antimicrobial activity. On the basis of these results, two series of novel selenoesters were synthesized to achieve more potent antibacterial activity on Gram-positive and Gram-negative bacteria. Fifteen selenoesters (eight ketone-selenoesters and seven cyano-selenoesters) were investigated with regards to their efflux pump-inhibiting, anti-quorum-sensing (QS), and anti-biofilm effects in vitro. According to the results of the antibacterial activity, the ketone-selenoesters proved to be more potent antibacterial compounds than the cyano-selenoesters. With regard to efflux pump inhibition, one cyano-selenoester on methicillin-resistant $S$. aureus and one ketone-selenoester on Salmonella Typhimurium were potent inhibitors. The biofilm inhibitory capacity and the ability of the derivatives to disrupt mature biofilms were noteworthy in all the experimental systems applied. Regarding QS inhibition, four ketone-selenoesters and three cyano-selenoesters exerted a noteworthy effect on Vibrio campbellii strains.
\end{abstract}

Keywords: selenoesters; Salmonella species; Staphylococcus aureus; Pseudomonas aeruginosa; biofilm; quorum sensing; multidrug resistance; antibacterial activity

\section{Introduction}

The rapid emergence of multidrug-resistant bacteria is jeopardizing the effectiveness of antibiotics that have saved millions of lives previously [1]. Microbes have become resistant to common antibiotics due to the irresponsible use of the antibiotics; therefore, the appearance of resistant bacterial strains makes the treatment of infections more complicated [2]. The improper use of antibiotics has also occurred in veterinary practice and in food-producing animal farms [3]. This has led to the 
emergence of superbugs that are resistant to several classes of antibiotics, such as carbapenem resistant Enterobacteriaceae [4] and biofilm-producing methicillin-resistant Staphylococcus aureus (MRSA) [5].

Numerous bacterial isolates produce biofilms, which are the surface-attached bacterial cells embedded into an extracellular matrix that can protect the bacterial population against antibiotics. These biofilm-producing bacteria are more resistant to antibiotics compared to the planktonic cells, which are more susceptible to biocides [6].

It was believed that bacteria are independent and unicellular organisms [7]. Nevertheless, planktonic growth of bacteria seldom exists in nature. It has been shown that bacteria in nature exist in a large, contiguous, and dynamic surface-associated community, called biofilm, and this population has a unique behavior, namely, the properties of the community depend on population density [8]. The cells in biofilms are in contact with each other. Bacteria in the biofilm secrete small extracellular molecules to communicate with each other [9]. Several bacteria have been shown to regulate different physiological processes and activities via a mechanism called quorum sensing (QS), in which bacterial cells produce, detect, and reply to small diffusible signal molecules [10]. It is known that these bacteria need to achieve a critical cell density before they express virulence factors and attack the host organism.

In addition, the over-expression of bacterial efflux pumps can also contribute to bacterial multidrug resistance (MDR). The efflux pumps are transmembrane transport proteins involved in the extrusion of toxic substances into the external milieu. Furthermore, these efflux pumps might be involved in the regulation of the expression of QS-dependent virulence factors. Therefore, the inhibition of efflux pumps may decrease the virulence of resistant bacteria [11].

Different selenocompounds and selenium nanoparticles have shown a significant antibacterial and anti-biofilm activity. Among the selenoparticles (SeNPs), SeNPs synthesized using aqueous berry extract of Murraya koenigii showed antibacterial activity against Enterococcus faecalis, Streptococcus mutans, Shigella sonnei, and Pseudomonas aeruginosa, as well as anti-biofilm activity against P. aeruginosa [12]. Alternatively, SeNPs conjugated with antibiotics were potent antibacterial agents and biofilm disruptors against MRSA [13]. Among selenocompounds, a series of steroidal $\beta$-hydroxy-phenylselenides also showed antibacterial activity against $P$. aeruginosa, and prevented its biofilm formation [14]. Similarly, ebselen derivatives were anti-biofilm and potent antibacterial agents against MRSA, with minimum inhibitory concentration (MIC) values below $2 \mu \mathrm{g} / \mathrm{mL}$ [15].

In this context, our group reported previously that selenoesters and selenoanhydrides are bioactive selenium-containing compounds initially designed as potential anticancer and MDR-reversing agents [16] with antioxidant activity [17]. Selenium (Se) and the Se-containing compounds are known antioxidants because this essential trace element allows the antioxidant activity of the glutathione peroxidase, the enzyme that empowers the deactivation of hydrogen peroxides [18-20]. In line with this, patients with bacterial and viral infections generally show high oxidative stress levels, as well as low levels of selenium in blood. Besides the reduction of this oxidative stress, Se can also boost the response of the immune system against infectious diseases [21,22]. The antibacterial activity of the abovementioned selenoesters and selenoanhydrides was evaluated, finding that they showed a potent antibacterial activity against MRSA, Salmonella enterica serovar Typhimurium, and Chlamydia trachomatis serovar D. Additionally, they exerted a noteworthy anti-biofilm activity, as well as being inhibitors of bacterial efflux pumps [23-25].

On the basis of these antecedents, we tested the antibacterial, anti-biofilm, and anti-quorum sensing activity of 15 selenoesters in this study, comprising 8 ketoneselenoesters $(\mathrm{R}=\mathrm{COCH}$, compounds K1-K8, Table 1 ) and 7 cyanoselenoesters ( $\mathrm{R}=\mathrm{CN}$, compounds N1-N7, Table 1 ). With our selenocompounds, we aimed to reduce the intercellular communication and thus reduce biofilm formation and reverse resistance. 
Table 1. Ketone- and cyano-selenoesters evaluated. Cpds. = Compounds.<smiles>[R]c1sc(C(=O)[Se][Ba])c([R])c1[R]</smiles>

Ring: Thiophene<smiles>[R][R8][Se]C(=O)c1ccc[R]([R])c1</smiles>

Ring: Benzene

\begin{tabular}{|c|c|c|c|c|c|c|c|c|c|c|c|}
\hline Cpds. & $\mathbf{R}^{\mathrm{Se}}$ & $\mathbf{R}^{1}$ & $\mathbf{R}^{2}$ & $\mathbf{R}^{3}$ & Ring & Cpds. & $\mathbf{R}^{\mathrm{Se}}$ & $\mathbf{R}^{1}$ & $\mathbf{R}^{2}$ & $\mathbf{R}^{3}$ & Ring \\
\hline K1 & $-\mathrm{CH}_{2} \mathrm{COCH}_{3}$ & $-\mathrm{H}$ & $-\mathrm{H}$ & $-\mathrm{H}$ & Thiophene & N1 & $-\mathrm{CH}_{2} \mathrm{CN}$ & $-\mathrm{H}$ & $-\mathrm{H}$ & $-\mathrm{H}$ & Thiophene \\
\hline K2 & $-\mathrm{CH}_{2} \mathrm{COCH}_{3}$ & $2-\mathrm{F}$ & $-\mathrm{H}$ & $-\mathrm{H}$ & Benzene & N2 & $-\mathrm{CH}_{2} \mathrm{CN}$ & $3-\mathrm{F}$ & $-\mathrm{H}$ & $-\mathrm{H}$ & Benzene \\
\hline K3 & $-\mathrm{CH}_{2} \mathrm{COCH}_{3}$ & $4-\mathrm{Br}$ & $-\mathrm{H}$ & $-\mathrm{H}$ & Benzene & N3 & $-\mathrm{CH}_{2} \mathrm{CN}$ & $4-\mathrm{Br}$ & $-\mathrm{H}$ & $-\mathrm{H}$ & Benzene \\
\hline K4 & $-\mathrm{CH}_{2} \mathrm{COCH}_{3}$ & $2-\mathrm{CF}_{3}$ & $-\mathrm{H}$ & $-\mathrm{H}$ & Benzene & $\mathrm{N} 4$ & $-\mathrm{CH}_{2} \mathrm{CN}$ & $2-\mathrm{CF}_{3}$ & $-\mathrm{H}$ & $-\mathrm{H}$ & Benzene \\
\hline K5 & $-\mathrm{CH}_{2} \mathrm{COCH}_{3}$ & $3-\mathrm{CF}_{3}$ & $-\mathrm{H}$ & $-\mathrm{H}$ & Benzene & N5 & $-\mathrm{CH}_{2} \mathrm{CN}$ & $3-\mathrm{CF}_{3}$ & $-\mathrm{H}$ & $-\mathrm{H}$ & Benzene \\
\hline K6 & $-\mathrm{CH}_{2} \mathrm{COCH}_{3}$ & $3-\mathrm{Cl}$ & $4-\mathrm{F}$ & $-\mathrm{H}$ & Benzene & N6 & $-\mathrm{CH}_{2} \mathrm{CN}$ & $3-\mathrm{Cl}$ & $4-\mathrm{F}$ & $-\mathrm{H}$ & Benzene \\
\hline K7 & $-\mathrm{CH}_{2} \mathrm{COCH}_{3}$ & $4-\mathrm{C}(\mathrm{CH})_{3}$ & $-\mathrm{H}$ & $-\mathrm{H}$ & Benzene & N7 & $-\mathrm{CH}_{2} \mathrm{CN}$ & & $5-\mathrm{CF}_{2}$ & $\mathrm{H}$ & \\
\hline K8 & $-\mathrm{CH}_{2} \mathrm{COCH}_{3}$ & $2-\mathrm{F}$ & $4-\mathrm{F}$ & $5-\mathrm{F}$ & Benzene & N7 & $-\mathrm{CH}_{2} \mathrm{CN}$ & 3 & $5-\mathrm{CF}_{3}$ & $-\mathrm{H}$ & Benzene \\
\hline
\end{tabular}

\section{Results}

\subsection{Determination of Minimum Inhibitory Concentrations by Microdilution Method}

On the basis of the results obtained on Gram-positive and Gram-negative bacteria, we found that the ketone-selenoesters demonstrated a strong antibacterial activity against the Gram-positive strains investigated. The most potent derivatives were $\mathbf{K 1}, \mathbf{K} 7$, and $\mathbf{K 8}$ - they were effective on all three $S$. aureus strains tested, even reaching the submicromolar range (MIC between 0.39 and $1.56 \mu \mathrm{M}$, Table 2).

Table 2. Antibacterial activity of selenoesters on Gram-positive and Gram-negative bacteria (S. aureus = Staphylococcus aureus, S. Typhimurium = Salmonella enterica serovar Typhimurium, $P$. aeruginosa $=$ Pseudomonas aeruginosa).

\begin{tabular}{|c|c|c|c|c|c|c|c|c|c|}
\hline \multirow[b]{2}{*}{ Cpds. } & \multicolumn{7}{|c|}{ MIC Determination $(\mu \mathrm{M})$} & \multirow[b]{2}{*}{$\begin{array}{c}P . \\
\text { aeruginosa } \\
\text { CCM } 3955\end{array}$} & \multirow[b]{2}{*}{$\begin{array}{c}P . \\
\text { aeruginosa } \\
\text { NEM 986 }\end{array}$} \\
\hline & $\begin{array}{c}\text { S. } \\
\text { aureus } \\
\text { ATCC } \\
25923\end{array}$ & $\begin{array}{l}\text { S. aureus } \\
\text { MRSA } \\
\text { ATCC } \\
43300\end{array}$ & $\begin{array}{c}\text { S. } \\
\text { aureus } \\
\text { MRSA } \\
272123\end{array}$ & $\begin{array}{c}S . \\
\text { Typhimurium } \\
\text { SE01 } \\
\text { Wild-Type }\end{array}$ & $\begin{array}{c}S . \\
\text { Typhimurium } \\
\text { SE02 } \\
\Delta a c r B\end{array}$ & $\begin{array}{c}S . \\
\text { Typhimurium } \\
\text { SE03 } \\
\Delta a c r A\end{array}$ & $\begin{array}{c}S . \\
\text { Typhimurium } \\
\text { SE39 } \\
\Delta \text { tolC }\end{array}$ & & \\
\hline K1 & 1.56 & 1.56 & 0.78 & 50 & 100 & 100 & 100 & 100 & 50 \\
\hline $\mathrm{K} 2$ & 1.56 & 3.125 & 0.78 & $>100$ & $>100$ & $>100$ & $>100$ & 100 & 50 \\
\hline K5 & 1.56 & 3.125 & 0.78 & 100 & 50 & 50 & $>100$ & 100 & 50 \\
\hline K6 & 1.56 & 3.125 & 0.39 & 100 & 100 & 100 & 100 & 100 & 50 \\
\hline K7 & 1.56 & 1.56 & 0.39 & 50 & $>100$ & 100 & $>100$ & 100 & 100 \\
\hline K8 & 1.56 & 1.56 & 0.78 & 50 & $>100$ & 100 & 100 & 100 & 50 \\
\hline N1 & 12.5 & 100 & 25 & 50 & 50 & 100 & 100 & $>100$ & $>100$ \\
\hline N2 & 12.5 & 100 & 50 & 50 & 100 & 100 & 100 & $>100$ & $>100$ \\
\hline N7 & 12.5 & 50 & 25 & 50 & 50 & 50 & 100 & $>100$ & $>100$ \\
\hline
\end{tabular}

Regarding the cyano-selenoesters, they were also more active on Gram-positive strains. Nevertheless, they were less effective on the MRSA strains (MIC: 25-100 $\mu \mathrm{M}$ ) compared to the methicillin-susceptible reference American Type Culture Collection (ATCC) 25923 strain (MIC: $12.5 \mu \mathrm{M}$ ). Considering this antibacterial potency, three out of the seven cyano-selenoesters evaluated seemed to be more powerful, namely, N3, N6, and N7. On the contrary, the ketone-selenoesters and the cyano-selenoesters were not effective on the tested P. aeruginosa strain and had a mild antibacterial activity on the $S$. Typhimurium strains investigated (MIC: 50-100 $\mu \mathrm{M}$ ) (Table 2). 


\subsection{Real-Time Ethidium Bromide Accumulation Assay}

In this study, the ketone- and cyano-selenoesters were tested for their ability to inhibit efflux pumps on Gram-negative and Gram-positive model bacterial strains (Table 3). The efflux pump inhibitor (EPI) activity was investigated on S. aureus ATCC MRSA 43300 and S. Typhimurium SE01, SE02, SE03, and SE39 strains. Regarding the Salmonella strains tested, the ketone-selenoester K7 was the most potent EPI because it increased the ethidium bromide (EB) accumulation in the efflux pump gene-inactivated mutant $S$. Typhimurium $(\triangle a c r A$ and $\triangle t o l C$ ) strains (relative fluorescence index (RFI): 1.15 and 1.67, respectively), probably because this compound may cause membrane destabilizing effects. It was observed that K7 inhibited the efflux activity of the wild-type SE01 strain as well (RFI: 1.02). The inhibition by $\mathbf{K} 7$ in $\Delta$ tolC strain was stronger than inhibition in the presence of the reference compound CCCP (carbonyl cyanide $\mathrm{m}$-chlorophenyl hydrazone). In addition, ketone-selenoesters K4 and K5 inhibited the EB accumulation in the tolC-inactivated mutant strain (Figure 1). Regarding cyano-selenoesters, the most pronounced activity was exerted by N4 and N7 on the tolC-inactivated mutant strain (Figure 2). The significance level was determined between the negative and positive controls and between the tested substances and the negative control.

Table 3. Efflux pump inhibitory effects of selenoesters on Staphylococcus aureus and S. Typhimurium strains in terms of RFI (relative fluorescence index) values. Higher RFI values indicate more efficient efflux pump inhibition.

\begin{tabular}{|c|c|c|c|c|c|c|}
\hline \multicolumn{7}{|c|}{ Relative Fluorescence Index (RFI) } \\
\hline Cpds. & $\begin{array}{l}\text { S. aureus MRSA } \\
\text { ATCC } 43300\end{array}$ & $\begin{array}{c}\text { S.aureus } \\
\text { ATCC } 25923\end{array}$ & $\begin{array}{c}\text { S. } \\
\text { Typhimurium } \\
\text { SE01 wild-type }\end{array}$ & $\begin{array}{c}S . \\
\text { Typhimurium } \\
\text { SE02 } \Delta a c r B\end{array}$ & $\begin{array}{c}S . \\
\text { Typhimurium } \\
\text { SE03 } \Delta a c r A\end{array}$ & $\begin{array}{c}S . \\
\text { Typhimurium } \\
\text { SE39 } \Delta \text { tolC }\end{array}$ \\
\hline K1 & -0.02 & 1.19 & 0.17 & 0.20 & 0.29 & 0.31 \\
\hline K2 & -0.04 & 1.12 & 0.18 & 0.21 & 0.30 & 0.42 \\
\hline K3 & -0.10 & 1.17 & 0.60 & 0.27 & 0.24 & 0.44 \\
\hline K4 & -0.09 & 1.02 & 0.19 & 0.35 & 0.68 & 0.95 \\
\hline K5 & -0.08 & 1.17 & 0.41 & 0.11 & 0.35 & 0.91 \\
\hline K6 & -0.09 & 1.19 & 0.17 & 0.43 & 0.52 & 0.80 \\
\hline K7 & -0.02 & 1.13 & 1.02 & 0.30 & 1.15 & 1.67 \\
\hline K8 & -0.04 & 1.10 & 0.08 & 0.31 & 0.28 & 0.70 \\
\hline N1 & 0.05 & 1.40 & 0.04 & 0.10 & 0.37 & 0.84 \\
\hline N2 & -0.02 & 1.31 & -0.06 & -0.05 & 0.16 & 0.19 \\
\hline N3 & -0.05 & 1.49 & 0.003 & 0.03 & 0.38 & 0.24 \\
\hline N4 & 0.35 & 1.78 & 0.22 & 0.39 & 0.36 & 1.00 \\
\hline N5 & -0.03 & 1.43 & 0.02 & 0.02 & 0.32 & 0.43 \\
\hline N6 & -0.01 & 1.32 & 0.03 & -0.03 & 0.45 & 0.38 \\
\hline N7 & -0.06 & 0.28 & 0.003 & 0.14 & 0.32 & 1.11 \\
\hline CCCP & - & - & 3.37 & 1.83 & 3.30 & 1.61 \\
\hline RES & 0.30 & 5.5 & - & - & - & - \\
\hline
\end{tabular}

In case of S. aureus ATCC MRSA 43300, only one derivative (the cyano-selenoester N4) showed a potent EPI activity (Figure 3); in addition, this effect was more pronounced (RFI: 0.351) than the one obtained in the presence of the reference EPI reserpine (RFI: 0.300). 

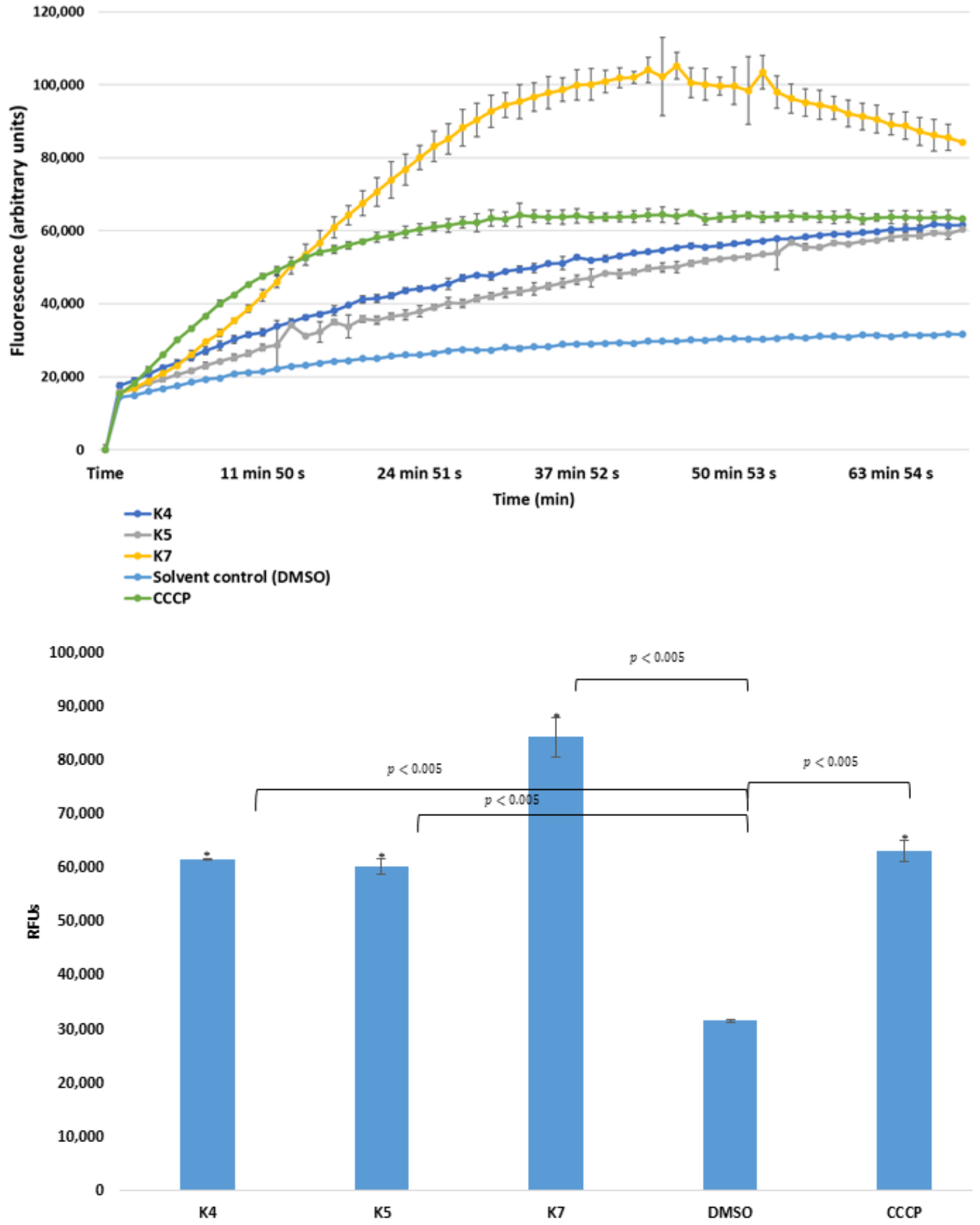

Figure 1. Accumulation of ethidium bromide (EB) in the presence of selenoesters $\mathbf{K 4}$, K5, and K7 on S. Typhimurium SE39 $\Delta$ tolC strain. DMSO: dimethyl sulfoxide (solvent); CCCP: carbonyl cyanide 3 -chlorophenylhydrazone (positive control). The level of significance was lower than $p=0.005$ in all cases; $\alpha=0.05 ; p$ values less than 0.005 are marked with an asterisk. 


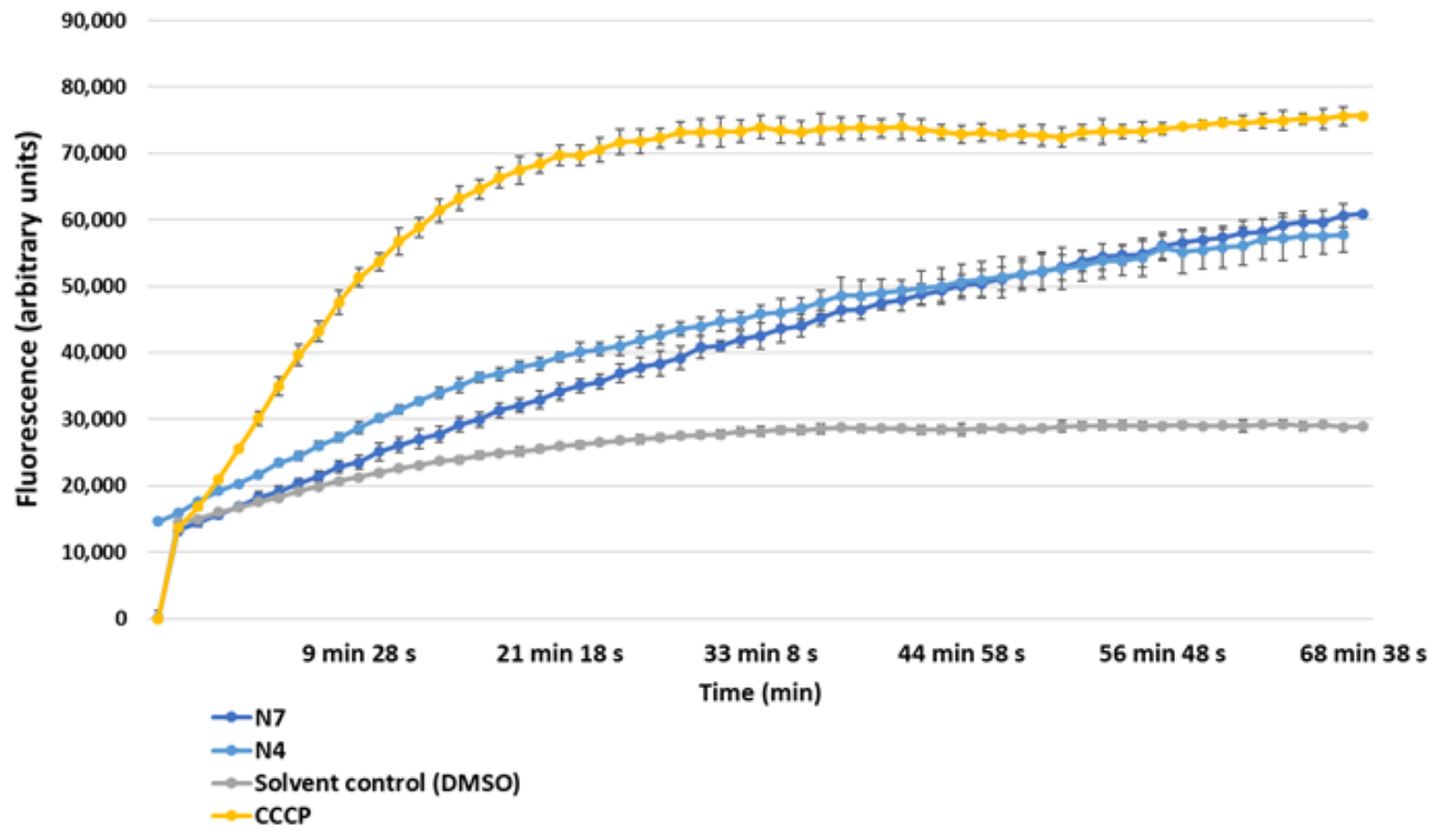

90,000

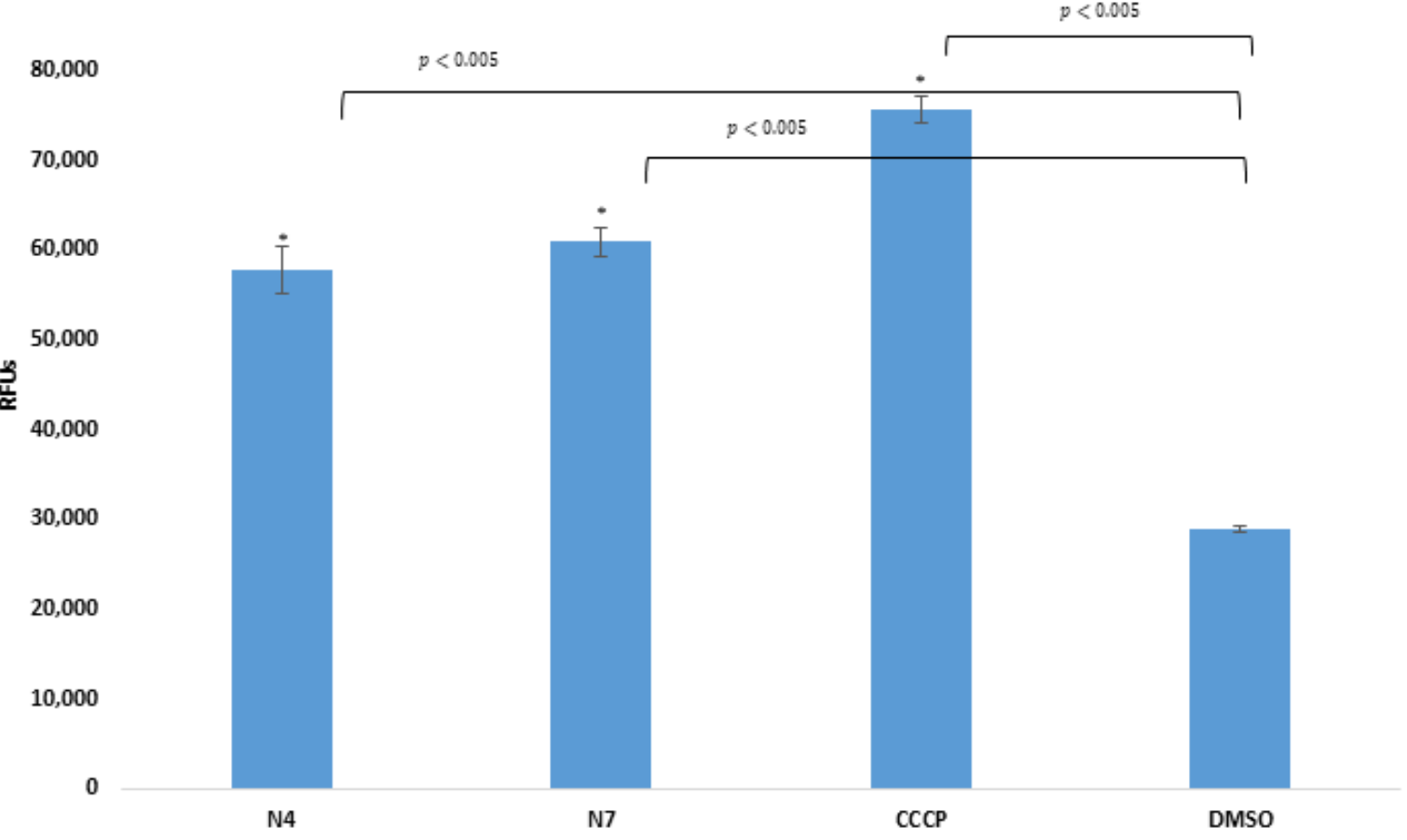

Figure 2. Accumulation of EB in the presence of N4 and N7 at one-half minimum inhibitory concentration (MIC) on S. Typhimurium SE39 $\Delta$ tolC strain. DMSO: dimethyl sulfoxide (solvent); CCCP: carbonyl cyanide 3-chlorophenylhydrazone (positive control). The level of significance was lower than $p=0.005$ in all cases; $\alpha=0.05 ; p$ values less than 0.005 are marked with an asterisk. 

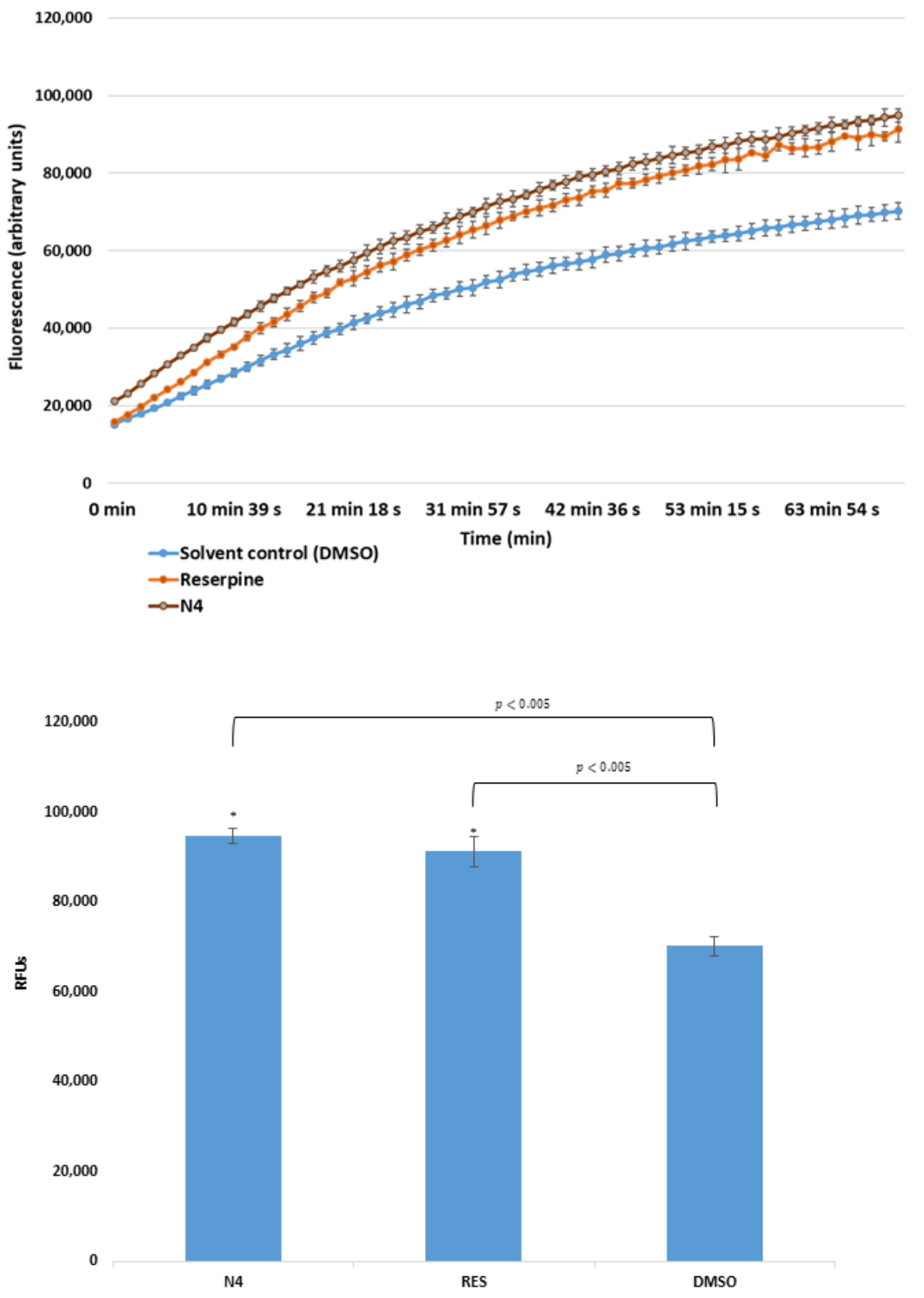

Figure 3. Accumulation of EB in the presence of selenoester N4 at one-half MIC on S. aureus MRSA (methicillin-resistant Staphylococcus aureus) 43300. DMSO: dimethyl sulfoxide (solvent); reserpine: positive control. The level of significance was lower than $p=0.005$ in all cases; $\alpha=0.05 ; p$ values less than 0.005 are marked with an asterisk.

\subsection{Assay for Quorum Sensing (QS) Inhibition}

In this case, the concentration that halves the viability $\left(\mathrm{IC}_{50}\right)$ was compared to the concentration halving the cell-to-cell communication $\left(\mathrm{EC}_{50}\right)$. This was a necessary step to differentiate between the toxic concentration and the quorum-sensing inhibiting concentration. If the dose for toxicity was higher than the dose needed for quorum sensing (QS) inhibition, the tested compound was considered efficient. Therefore, the comparison of toxicity and QS inhibiting concentrations was evaluated by means of the selectivity index (SI), which was calculated as the ratio of $\mathrm{IC}_{50}$ and $\mathrm{EC}_{50}$. A higher index is related to a more potent efficacy of the compound in QS inhibition. As can be seen in Table 4, all tested compounds (except for the compound N5) were able to inhibit the bacterial communication. 
Table 4. Anti-quorum sensing effects of selenocompounds on Vibrio strains.

\begin{tabular}{ccccccc}
\hline \multirow{2}{*}{ Cpd. } & \multicolumn{3}{c}{ Vibrio campbellii BAA 1118 } & \multicolumn{3}{c}{ Vibrio campbellii BAA 1119 } \\
\cline { 2 - 7 } & IC $_{\mathbf{5 0}}(\boldsymbol{\mu M})$ & $\mathbf{E C}_{\mathbf{5 0}}(\boldsymbol{\mu M})$ & SI & IC $_{\mathbf{5 0}}(\mu \mathrm{M})$ & EC $_{\mathbf{5 0}}(\boldsymbol{\mu M})$ & SI \\
\hline K1 & $5.76 \pm 0.07$ & $0.22 \pm 0.01$ & 26.2 & $2.02 \pm 0.15$ & $0.71 \pm 0.05$ & 2.8 \\
K2 & $4.38 \pm 0.47$ & $0.25 \pm 0.03$ & 17.5 & $3.23 \pm 0.14$ & $0.22 \pm 0.02$ & 14.7 \\
K3 & $1.12 \pm 0.02$ & $0.17 \pm 0.01$ & 6.6 & $0.77 \pm 0.07$ & $0.23 \pm 0.02$ & 3.3 \\
K4 & $33.18 \pm 3.45$ & $4.68 \pm 0.32$ & 7.1 & $6.66 \pm 0.13$ & $0.29 \pm 0.05$ & 23.0 \\
K5 & $2.42 \pm 0.29$ & $1.35 \pm 0.03$ & 1.8 & $1.32 \pm 0.10$ & $0.45 \pm 0.01$ & 2.9 \\
K6 & $3.28 \pm 0.19$ & $2.29 \pm 0.02$ & 1.4 & $0.97 \pm 0.09$ & $1.20 \pm 0.00$ & 0.8 \\
K7 & $10.54 \pm 0.19$ & $1.77 \pm 0.19$ & 6.0 & $4.27 \pm 0.23$ & $0.15 \pm 0.01$ & 28.5 \\
K8 & $1.23 \pm 0.07$ & $0.11 \pm 0.01$ & 11.2 & $1.39 \pm 0.03$ & $0.46 \pm 0.03$ & 3.0 \\
\hline N1 & $2.21 \pm 0.19$ & $1.45 \pm 0.02$ & 1.5 & $2.28 \pm 0.12$ & $0.26 \pm 0.03$ & 8.8 \\
N2 & $7.36 \pm 0.70$ & $0.34 \pm 0.04$ & 21.6 & $2.40 \pm 0.12$ & $0.73 \pm 0.02$ & 5.1 \\
N3 & $2.199 \pm 0.16$ & $0.34 \pm 0.04$ & 6.5 & $2.35 \pm 0.03$ & $<0.06$ & 37.6 \\
N4 & $2.52 \pm 0.03$ & $1.29 \pm 0.04$ & 2.0 & $6.41 \pm 0.42$ & $0.73 \pm 0.02$ & 8.8 \\
N5 & $12.51 \pm 0.05$ & $>5$ & - & $3.57 \pm 0.08$ & $>5$ & - \\
N6 & $1.37 \pm 0.02$ & $0.37 \pm 0.05$ & 3.7 & $2.28 \pm 0.12$ & $0.22 \pm 0.00$ & 10.4 \\
N7 & $3.84 \pm 0.15$ & $1.44 \pm 0.06$ & 2.7 & $7.71 \pm 0.10$ & $0.25 \pm 0.02$ & 30.8 \\
\hline
\end{tabular}

Usually, for the practical application, indexes should be higher than 10 [26]. On the basis of this criterion, the promising ketone-selenoesters are $\mathbf{K 1}, \mathbf{K} \mathbf{2}$, and $\mathbf{K} \mathbf{8}$, whereas the most effective cyano-selenoester is $\mathbf{N 2}$. The ability of selenocompounds to inhibit quorum sensing was tested using two strains of Vibrio campbellii. The wild-type of these bacteria uses both autoinducer-1 (AI-1) and autoinducer-2 (AI-2) types of molecules for its communication. Strain 1118 is deficient in communication on the basis of AI-2, while strain 1119 is deficient in AI-1 type communication. Out of the tested compounds, only $\mathbf{K} 2$ was able to inhibit the communication on the basis of either AI-1 or AI-2 molecules, with a selectivity index higher than 10 (17.5 and 14.7, respectively). The ketone-selenoester K1 resulted in being the most promising compound in the inhibition of AI-1-based communication showing the SI of 26.2. The second most potent AI-1 inhibitor was N2 (SI = 21.6), which was also the only cyano-selenoester capable of inhibiting AI-1-based communication. In contrast, the cyano-selenocompounds were more effective inhibitors of AI-2-based communication, with N3 (SI = 37.6) and N7 (SI = 30.8) being the most effective compounds among them (Table 4).

\subsection{Anti-Biofilm Activity}

The anti-biofilm activity was evaluated against typical pathogenic bacteria known for biofilm formation, such as the Gram-positive S. aureus and the Gram-negative P. aeruginosa. The ability of the compounds to affect the biofilm formation (the inhibition of cell adhesion) was tested, followed by the determination of their ability to disrupt mature biofilms. As can be seen in Table 5, all of the tested compounds were able to affect both stages of the biofilm formation. As is known, biofilm is a layer of cells protected from the adverse external conditions; therefore, the concentrations needed to halve the mature biofilm are several times higher than those needed for halving the adhesion of bacteria. This difference was most pronounced for compound N3, which required up to 26- and 11-fold higher concentration for achieving the disruption of the biofilm produced by S. aureus and $P$. aeruginosa, respectively, compared to the concentrations at which the inhibition of the adhesion takes place. In contrast, compound $\mathbf{K} 5$ possessed the least noticeable difference in cell adhesion and biofilm disruption, which was only five and four times higher for S. aureus and P. aeruginosa, respectively. Almost in all cases, the selenocompounds evaluated were slightly more active against $P$. aeruginosa than against $S$. aureus. 
Table 5. Concentration of selenoesters halving $\left(\mathrm{IC}_{50}\right)$ the adhesion and disrupting the biofilm of $S$. aureus ATCC 25923 and P. aeruginosa CCM 3955 strains.

\begin{tabular}{ccccc}
\hline \multirow{2}{*}{ Compounds } & \multicolumn{2}{c}{ Staphylococcus aureus ATCC 25923 } & \multicolumn{2}{c}{ Pseudomonas aeruginosa CCM 3955 } \\
\cline { 2 - 5 } & Anti-Adhesion $(\mu \mathbf{M})$ & Anti-Biofilm $(\mu \mathbf{M})$ & Anti-Adhesion $(\mu \mathrm{M})$ & Anti-Biofilm $(\mu \mathrm{M})$ \\
\hline K1 & $1.84 \pm 0.26$ & $32.80 \pm 3.25$ & $1.15 \pm 0.01$ & $10.21 \pm 0.48$ \\
K2 & $1.72 \pm 0.17$ & $28.08 \pm 1.17$ & $1.10 \pm 0.11$ & $8.78 \pm 0.66$ \\
K3 & $1.39 \pm 0.13$ & $11.64 \pm 0.99$ & $1.14 \pm 0.05$ & $6.00 \pm 0.74$ \\
K4 & $3.59 \pm 0.48$ & $28.70 \pm 4.18$ & $3.04 \pm 0.33$ & $21.85 \pm 2.04$ \\
K5 & $2.84 \pm 0.13$ & $15.44 \pm 0.42$ & $1.51 \pm 0.22$ & $6.45 \pm 0.30$ \\
K6 & $2.96 \pm 0.16$ & $12.87 \pm 0.37$ & $2.33 \pm 0.25$ & $14.29 \pm 1.62$ \\
K7 & $3.08 \pm 0.24$ & $40.80 \pm 3.12$ & $2.16 \pm 0.29$ & $11.06 \pm 1.92$ \\
K8 & $1.35 \pm 0.16$ & $9.22 \pm 0.61$ & $0.86 \pm 0.09$ & $6.98 \pm 0.22$ \\
\hline N1 & $2.46 \pm 0.15$ & $24.79 \pm 2.65$ & $1.78 \pm 0.07$ & $15.51 \pm 1.65$ \\
N2 & $3.14 \pm 0.12$ & $48.08 \pm 3.82$ & $2.86 \pm 0.17$ & $18.06 \pm 0.72$ \\
N3 & $1.19 \pm 0.15$ & $30.46 \pm 2.72$ & $0.92 \pm 0.01$ & $10.56 \pm 0.95$ \\
N4 & $1.49 \pm 0.08$ & $28.91 \pm 2.00$ & $2.49 \pm 0.43$ & $13.48 \pm 0.82$ \\
N5 & $3.01 \pm 0.35$ & $34.55 \pm 3.00$ & $3.40 \pm 0.10$ & $24.81 \pm 2.12$ \\
N6 & $1.83 \pm 0.15$ & $21.75 \pm 2.61$ & $1.34 \pm 0.08$ & $13.46 \pm 1.77$ \\
N7 & $1.99 \pm 0.26$ & $16.53 \pm 0.76$ & $1.81 \pm 0.04$ & $11.09 \pm 0.82$ \\
\hline
\end{tabular}

\section{Discussion}

\subsection{Antibacterial Activity}

Previously, it was described by our group that a methylketone selenoester had antibacterial activity against Gram-positive bacteria, and two selenocompounds (a selenoanhydride and a diselenodiester) were active inhibitors of the AcrAB-TolC system [25]. In addition, a series of symmetrical selenoesters were investigated with respect to their anti-biofilm and efflux pump-inhibiting properties. In this study, we observed that the methyloxycarbonyl selenoesters showed a significant biofilm and efflux pump inhibition, and that a strong QS inhibiting activity was exerted by a methyloxycarbonyl selenoester [24].

As a continuation of our former studies, we synthesized new classes of Se-containing compounds and investigated them as potential antibacterial agents in this work. According to the results of the antibacterial activity, the ketone-selenoesters proved to be more potent antibacterial compounds than the cyano-selenoesters against the strains of Staphylococcus aureus evaluated. The ketone-selenoesters exerted potent activity on sensitive and methicillin-resistant $S$. aureus strains. Interestingly, the cyano-selenoesters were slightly more active than the ketone-selenoesters against the Salmonella enterica serovar Typhimurium strains evaluated-the seven cyano-selenoesters tested showed MIC values of 50 or $100 \mu \mathrm{M}$, whereas half of the eight ketone-containing selenoesters had MIC values above $100 \mu \mathrm{M}$. None of the 15 derivatives had antibacterial activity on Pseudomonas aeruginosa.

A few structure-activity relationships (SAR) can be concluded on the basis of the activity of ketone-selenoesters against $S$. aureus, taking into account that the number of compounds was not enough and thus more experiments should be performed in the future in order to confirm these empirical observations. The most active compound was K6, which had a tert-butyl group in para-position, with MIC values of $1.56 \mu \mathrm{M}$ on the sensitive strains and $0.39-3.13 \mu \mathrm{M}$ for the MRSA strains. K6 was the unique compound with an electron-donating substituent in this work, as previous evaluations of selenoesters pointed out that electron-withdrawing substituents generally showed higher biological activity. Further studies should explore additional compounds with electron-donating substituents to confirm if they have higher antibacterial activity against $S$. aureus. In any case, the differences were small, as K1 (unsubstituted), K6 (3-chloro-4-fluoro substituted), and K8 (2,4,5-trifluoro substituted) showed similar MIC values on two $S$. aureus bacterial strains.

Among the nitrile derivatives N1-N7, all exerted similar activity $(\mathrm{MIC}=12.5 \mu \mathrm{M})$ against the sensitive S. aureus ATCC 25923 strain. Taking together the results on the MRSA and S. Typhimurium strains, the most active ones were N1 (unsubstituted), N3 (4-Br-substituted), N6 (3-Cl-substituted), and 
N7 (3,5-bis(trifluoromethyl)-substituted). These data suggest that, among monosubstituted compounds, those that include a bromine or a chlorine atom bound to the ring have better activity than those with a fluoro or a trifluoromethyl group, and that the inclusion of a second trifluoromethyl group contributes to an antibacterial activity similar to the one observed for the bromine or chlorine derivatives.

It is noteworthy to mention that the less active compound (K4) had a bulky substituent (trifluoromethyl group) at the ortho position of the selenoester. This fact may produce a steric hindrance that may hamper the hydrolysis of the selenoester inside the cells, which is the suggested mechanism underlying the biological activity [16]. When this bulky substituent was replaced by the smallest possible substituent (-H in compound K1), the MIC value was twofold lower on the three strains of $S$. aureus tested. Additionally, its replacement by a fluorine atom (intermediate between $-\mathrm{H}$ and $-\mathrm{CF}_{3}$ ) led to a twofold MIC reduction on S. aureus ATCC 25923 and in S. aureus MRSA 272123, but maintaining the MIC value on the third strain (S. aureus MRSA 43300). In this case, the inclusion of additional $-\mathrm{F}$ atoms at positions -4 and -5 (selenoester K8) managed to reduce the MIC value on the third strain, achieving an activity comparable to K1. Interestingly, the same effect of the steric hindrance was observed in the cyano-selenoesters between the compounds with a 2-CF $(\mathbf{N} 4)$ and a 2-H (N1); as in the ketone derivatives, the bulky derivative was less active than the unsubstituted derivative.

\subsection{Efflux Pump Inhibitory Asssay}

Multidrug resistance due to drug efflux mechanisms protects bacteria through the extrusion of antibiotics out of the bacterial cells. Thus, this efflux-related phenomenon can make bacterial infections untreatable due to the lack of activity of the antibiotics. Thus, a promising strategy to restore the sensitivity of bacteria to antibiotics could be their administration together with efflux pump inhibitors, also known as EPIs [27].

In order to reverse the multidrug-resistant phenotype and re-sensitize multidrug-resistant bacteria to antibiotic therapy, the application of EPIs is an adequate approach, and natural and synthetic molecules have been described as EPIs against Gram-negative and Gram-positive bacteria [27]. Regarding the present ketone- and cyano-selenoesters, only one cyano-selenoester-N4 - showed a potent EPI activity on methicillin-resistant $S$. aureus; furthermore, this inhibition was stronger than the effect of the reference EPI reserpine. In addition, ketone-selenoester K7 was an effective EPI on Salmonella Typhimurium strains, supposedly due to its membrane-destabilizing activity. Interestingly, all of the compounds that have at least one trifluoromethyl group (K4, K5, N4, and N7), with the exception of N5, showed moderate efflux pump inhibitory effects on $S$. Typhimurium SE39 $\Delta$ tolC strain in terms of the real-time ethidium bromide accumulation assay. Consequently, this $-\mathrm{CF}_{3}$ moiety and the $-\mathrm{C}\left(\mathrm{CH}_{3}\right)_{3}$ moiety of $\mathbf{K} 7$ seemed to be relevant for this efflux pump inhibition activity in $S$. Typhimurium SE39 $\Delta$ tolC strain.

In this work, we explored the ability of the compounds to inhibit efflux pumps, and at the sight of the promising inhibitory results obtained, we wanted to explore whether the compounds were able to synergistically enhance the activity of commercial antibiotics against multidrug-resistant bacterial strains.

\subsection{Quorum Sensing (QS) Inhibition and Anti-Biofilm Assay}

Inhibition of bacterial cell to cell communication finds its application in the prevention and spreading of bacterial infections. The communication is used by bacteria to sense their count, and in specific breakpoints, they switch their behavior and start to produce biofilm, thus regulating their virulence and metabolism [28]. Nowadays, the quorum-sensing modulators offer new tools in the fight against bacterial resistance and in the diagnosis of the disease, and also act as novel antimicrobial agents. Quorum sensing is based on three types of molecules: homoserine lactones, peptides, and boron structures. AI-1 communication is based on homoserine lactones and is provided by LuxI protein, which is responsible for AI production, and LuxR protein, which becomes activated by AI [29]. AI-2 communication is based on boron structures, which are produced by LuxS, and recognized 
by the sensor kinase. Usually, the communication of Gram-negative bacteria is due to the homoserine lactones, whereas Gram-positive bacteria use peptides as AI-1 type of molecules. AI-2 molecules are more universal and serve for communication in both Gram-positive and Gram-negative bacteria. While the homoserine lactones can diffuse freely across the cell membrane, peptide autoinducers usually require special transport mechanisms. These transport mechanisms are generally provided by ABC transporters (ATP-binding cassette), which are similar to those used by mammalian cells as efflux pumps. The inhibitors of the bacterial communication based on peptides could therefore find an application in the inhibition of the related-mammalian ABC transporters, whose overproduction is responsible for, e.g., chemotherapeutic-resistant cancer or drug-resistant epilepsy [30].

On the basis of our results, several compounds appear promising for their use as communication inhibitors. Compound $\mathrm{K} 2$ inhibited both types of communication with a significant selectivity to inhibit communication rather than growth of bacteria. This selectivity is favorable for non-pathogenic (symbiotic) bacteria that constitute the human microflora. The ketone-selenoester K1 was evaluated as the most promising compound inhibiting AI-1-based communication, followed by N2, which was the only cyano-selenocompound that was capable of inhibiting this AI-1-based communication. Both $\mathrm{K} 1$ and $\mathbf{N} 2$ were able to inhibit the communication at concentrations as low as 0.25 and $0.34 \mu \mathrm{M}$, respectively. Furthermore, both the ketone-selenoester $\mathbf{K} 2$ and the cyano-selenoester N2 share a 2-fluorophenyl moiety bound to the selenoester, which seems important for this inhibition of AI-1 communication. Interestingly, the substitution with fluorine atoms in the absence of other substituents was profitable for the activity, as the fourth most active compound was the one with a 2,4,5-trifluoro substitution. Alternatively, the activity of the unsubstituted derivative K1 (the most active inhibitor) may not be related to the lack of substitution because its nitrile equivalent (N1) is devoid of activity. The communication of P. aeruginosa is usually based on homoserine lactones (AI-1); therefore, its adhesion should be dominantly inhibited by the same compounds inhibiting AI-1-based communication of V. campbellii (strain BAA 1118). Compounds K1, K2, and K8 showed QS selectivity indexes higher than 10 , and they were also the most active inhibitors of the adhesion of P. aeruginosa in the anti-biofilm assay.

Otherwise, the cyano-selenocompounds were more effective in the inhibition of AI-2-based communication-N3 and N7 were the most effective compounds among the others, with N3 being capable of exerting its inhibition at a concentration as low as $60 \mathrm{nM}$. Intriguingly, they had a quite different substitution at the phenyl ring than the compounds active in AI-1—a bulky bromine atom (N3) or a more bulky di-substitution with trifluoromethyl groups (N7). Furthermore, the two more potent inhibitors among the ketone-selenoesters also included bulky substituents-trifluoromethyl (K4) or tert-butyl (K7) derivatives that support this observation. Compound K2, with a fluorine atom, was also active, but with a selectivity index (SI) of 14.7, significantly lower than the ones of N3, N7, K4, and K7: 37.6, 30.8, 23.0, and 28.5, respectively.

Quorum sensing of Gram-positive bacteria is usually based on peptide molecules, which are not typical of Vibrio communication; therefore, these results could not be correlated. However, many of tested compounds showed a significant inhibition of $S$. aureus adhesion; thus, the Se-compounds should be investigated more in depth to determine their ability to modulate the activity of ABC transporters. Autoinducers-2 are commonly used by many Gram-positive and Gram-negative bacteria. For example, S. aureus, bacteria belonging to the Enterobacteriaceae family or to the genus Bacillus, use the ABC transporters as a part of their communication [31]. However, in the AI-2 system, these transporters are used for uptake of communication molecules [32]. This universal system of communication spreading in both Gram-positive and Gram-negative bacteria was significantly inhibited by compounds K2, K4, K7, N3, N6, and N7.

Regarding the anti-biofilm assay, all compounds were able to prevent the biofilm adhesion in the two bacterial strains evaluated (S. aureus ATCC 25923 and P. aeruginosa CCM 3955) at concentrations below $4 \mu \mathrm{M}$. Two of them (K8 and N3) exerted this inhibition of the P. aeruginosa biofilm at nanomolar range: $0.86 \mu \mathrm{M}$ and $0.92 \mu \mathrm{M}$, respectively. Seven additional compounds exerted this effect at 
concentrations from 1 to $2 \mu \mathrm{M}$ in $P$. aeruginosa, whereas eight showed this range of activity against S. aureus. A tendency can be observed-the compounds monosubstituted with halogens (K1-K3, N1-N3), with the exception of N1 and N2, tended to have anti-adhesion activity at concentrations below $2 \mu \mathrm{M}$. In the anti-biofilm evaluation, all compounds were disruptors of existing biofilms at concentrations below $25 \mu \mathrm{M}$ in P. aeruginosa, and below $50 \mu \mathrm{M}$ in S. aureus. Out of them, K2, K3, K5, and $\mathrm{K} 8$ disrupted the biofilm at concentrations below $10 \mu \mathrm{M}$ in P. aeruginosa, and $\mathrm{K} 8$ in S. aureus. In this case, no SARs could be extracted, and besides this, the ketone-selenoesters resulted in being more potent disruptors than the cyano-selenoesters; moreover, the compounds were more effective against $P$. aeruginosa biofilms than against those of $S$. aureus.

\section{Materials and Methods}

\subsection{Compounds}

The 15 selenoesters evaluated in this work were previously synthesized and evaluated as described at the patent application EP17382693 [33]. Briefly, a selenation of an acyl chloride was initially performed in aqueous media, being the selenating agent, and sodium hydrogen selenide was prepared in situ by reduction of metallic selenium with sodium borohydride. Later, the intermediate generated, with no purification (one-pot synthesis), reacted with the adequate alkyl halide to render the desired selenoester. When necessary for not being commercially available, the acyl chloride was synthesized by the chlorination of the corresponding carboxylic acid using thionyl chloride.

Before each biological assay, the stock solution of selenoesters $(10 \mathrm{mM})$ was prepared in dimethyl sulfoxide (DMSO).

\subsection{Reagents and Media}

DMSO (Sigma-Aldrich, St Louis, MO, USA), phosphate-buffered saline (PBS; pH 7.4), Mueller-Hinton $(\mathrm{MH})$ broth, autoinducer bioassay (AB-A) medium, resazurin sodium salt (Sigma-Aldrich), tryptic soy broth (TSB), tryptic soy agar (TSA), brain heart infusion (BHI), Luria-Bertani broth (LBB), Luria-Bertani agar (LBA), reserpine, CCCP (carbonyl cyanide 3-chlorophenylhydrazone).

\subsection{Bacterial Strains}

As Gram-positive strains, Staphylococcus aureus American Type Culture Collection (ATCC) 25923 strain was used as methicillin-susceptible reference and biofilm-producing strain; the clinical isolate S. aureus MRSA 272123 and the methicillin and oxacillin-resistant S. aureus MRSA ATCC 43300 strains were investigated in the study.

As Gram-negative strains, the biofilm-producing Pseudomonas aeruginosa CCM 3955/ATCC 27853, multidrug-resistant P. aeruginosa NEM 986 strain, the wild-type Salmonella enterica serovar Typhimurium SL1344 (SE01) expressing the AcrAB-TolC pump system and its acrB gene-inactivated mutant S. Typhimurium SL1344 strain (SE02), acrA gene-inactivated mutant S. Typhimurium SL1344 (SE03), and tolC gene-inactivated mutant $S$. Typhimurium SL1344 strain (SE39) were used in the study. In terms of QS tests, the Gram-negative Vibrio campbellii ATCC BAA-1118 and ATCC BAA-1119 strains were applied. Microorganisms were obtained from the Czech Collection of Microorganisms (CCM, Masaryk University, Czech Republic) and the Collection of Laboratory of Medical Microbiology (NEM, Czech Laboratory, Ltd., Prague, Czech Republic).

\subsection{Determination of Minimum Inhibitory Concentrations (MIC) by Microdilution Method}

The minimum inhibitory concentrations (MICs) of ketone- and cyano-selenoesters were obtained according to the Clinical and Laboratory Standard Institute guidelines (CLSI) [34]. The MIC values of the compounds were established by visual inspection. The solvent DMSO did not exert any antibacterial activity. The MIC determination was performed in 4 parallels for each compound and strain, respectively. 


\subsection{Real-Time Ethidium Bromide Accumulation Assay}

The efflux pump inhibiting activity of Se-compounds was tested on S. aureus ATCC 25923 and S. aureus MRSA ATCC 43300 strains by real-time fluorimetry monitoring the intracellular accumulation of the efflux pump substrate EB using a CLARIOstar Plus plate reader (BMG Labtech, Ortenberg, Germany). Reserpine (RES) was applied at $25 \mu \mathrm{M}$ as a positive control; the solvent DMSO was applied at $1 \mathrm{v} / \mathrm{v} \%$. The bacterial strains were cultured at $37^{\circ} \mathrm{C}$ in a shaking incubator until they reached an optical density (OD) of 0.6 at $600 \mathrm{~nm}$. The cells were then washed with phosphate-buffered saline (PBS; $\mathrm{pH} 7.4$ ) and centrifuged at $13,000 \times g$ for $2 \mathrm{~min}$; the pellet was re-suspended in PBS. The Se-compounds were applied at one-half MIC concentration to PBS supplemented with a non-toxic concentration of EB $(2 \mu \mathrm{g} / \mathrm{mL})$. Then, the solutions were pipetted into a 96-well black microtiter plate (Greiner Bio-One Hungary Kft, Hungary), and $50 \mu \mathrm{L}$ of bacterial suspension ( $\left.\mathrm{OD}_{600} 0.6\right)$ was pipetted to the wells. Then, the plates were inserted into the CLARIOstar plate reader, and the fluorescence was recorded at excitation and emission wavelengths of $530 \mathrm{~nm}$ and $600 \mathrm{~nm}$, respectively, every minute for 1 hour. From the real-time data, the relative fluorescence index (RFI) of the last time point (minute 60) of the EB accumulation assay was calculated according to the subsequent equation:

$$
\mathrm{RFI}=\left(\mathrm{RF}_{\text {treated }}-\mathrm{RF}_{\text {untreated }}\right) / \mathrm{RF}_{\text {untreated }}
$$

where $\mathrm{RF}_{\text {treated }}$ is the relative fluorescence $(\mathrm{RF})$ at the last time point of $\mathrm{EB}$ retention curve in the presence of an inhibitor, and $\mathrm{RF}_{\text {untreated }}$ is the $\mathrm{RF}$ at the last time point of the EB retention curve of the untreated control having the solvent control (DMSO) [24]. The RFI values were analyzed by $t$-test, and statistical significance was defined as $p<0.05$.

\subsection{Assay for Quorum Sensing (QS) Inhibition}

Anti-QS activity was monitored by two commercial strains of $V$. campbellii (ATCC BAA-1118 and ATCC BAA-1119). The first one responds by bioluminescence to AI-1 inducer, the second one to AI-2 inducer [35]. The effect of compounds on the luminescence generation was evaluated as described previously. Briefly, the overnight culture of strains was diluted to $5 \times 10^{5} \mathrm{CFU} / \mathrm{mL}$ (colony-forming units per milliliter) in Autoinducer Bioassay medium (( $\mathrm{NaCl}(17.5 \mathrm{~g} / \mathrm{L}), \mathrm{MgSO} 4$ (12.3 g/L), casamino acids (2 g/L), $10 \mathrm{mM}$ potassium phosphate ( $\mathrm{pH} 7.0), 1 \mathrm{mM}$ L-arginine, and glycerol (10 mL/L of each)) and split into 96-well plates. After adding the compounds and their twofold serial dilutions, we incubated the plate for $8 \mathrm{~h}$ at $30^{\circ} \mathrm{C}$ with continuous shaking. Then, luminescence was recorded for $16 \mathrm{~h}$ using a microplate reader (SpectraMax i3 Multi-Mode Detection Platform, Molecular Devices, San Jose, CA, USA) set up at $30^{\circ} \mathrm{C}$, integration time of $10,000 \mathrm{~ms}$, and shaking for $60 \mathrm{~s}$ prior to measurement. The $\mathrm{EC}_{50}$ of compounds was determined on the basis of the sum of luminescence. After that, the viability of culture was determined by resazurin assay and the $\mathrm{IC}_{50}$ of compounds was calculated. The compounds were compared on the basis of $\mathrm{EC}_{50}$ (the concentration that halves the cell communication) and $\mathrm{IC}_{50}$ (viability). The $\mathrm{EC}_{50}$ and $\mathrm{IC}_{50}$ were calculated by using GraphPad Prism software version 5.00 for Windows with nonlinear regression curve fit (GraphPad Software, San Diego, CA, USA; www.graphpad.com).

\subsection{Anti-Biofilm Activity}

\subsubsection{Inhibition of Biofilm Formation}

The effect of the Se-compounds on biofilm formation was investigated on S. aureus ATCC 25923 and P. aeruginosa CCM 3955 (ATCC 27853). The experiment was carried out in 96-well microplates [36]. The overnight bacterial was diluted in brain heart infusion (BHI) broth to achieve the optical density of $0.5 \mathrm{McF}$ arland, and the suspension was distributed into 96-well plates in $100 \mu \mathrm{L}$ aliquots per well. The Se-compounds were pipetted to the cells in a concentration range of $100 \mu \mathrm{M}$ to $3.125 \mu \mathrm{M}$. The plate was kept for $24 \mathrm{~h}$ at $37^{\circ} \mathrm{C}$. Then, the viability of adherent cells was determined immediately by 
resazurin assay. The medium was discarded, the samples were washed 3 times by phosphate-buffered saline (PBS), and $100 \mu \mathrm{L}$ of resazurin in PBS $(0.03 \mathrm{mg} / \mathrm{L})$ was added to the wells [37]. The viability was measured by recording the fluorescence (560/590 nm, ex./em.) by the SpectraMax i3x Multi-Mode Detection Platform (Molecular Devices, San Jose, CA, USA). The assays were performed in four parallels. The relative viability was evaluated as a percentage according to the formula:

$$
\mathrm{RA}[\%]=100 \frac{\text { sample fluorescence }- \text { average fluorescence of } \mathrm{NC}}{\text { average fluorescence of } \mathrm{PC}-\text { average fluorescence of } \mathrm{NC}}
$$

where RA is relative activity in percentage, PC is positive control (untreated biofilm), and NC is negative control (resazurin incubated without bacterial cells).

The $\mathrm{IC}_{50}$ values were calculated using the online tool freely provided by AAT Bioquest-IC50 Calculator.

\subsubsection{Disruption of Mature Biofilm}

The activity of Se-compounds to damage mature biofilms formed by S. aureus ATCC 25923 or P. aeruginosa CCM 3955 (ATCC 27853) was investigated by resazurin assay [38]. The assay was carried out in 96-well plates. The overnight bacterial cultures were diluted in BHI broth to the optical density of $0.5 \mathrm{McF}$ arland and pipetted in $100 \mu \mathrm{L}$ aliquots into the wells. After $24 \mathrm{~h}$ of incubation at $37^{\circ} \mathrm{C}$, the medium was discarded, and fresh BHI broth containing Se-compounds was measured to the wells. After $24 \mathrm{~h}$ of incubation, the medium was discarded, the wells were washed 3 times by PBS (pH 7.4), and $100 \mu \mathrm{L}$ of resazurin in PBS $(0.03 \mathrm{mg} / \mathrm{L})$ was measured to the samples. The viability was recorded by measuring fluorescence (560/590 nm, ex./em.) using the SpectraMax i3x Multi-Mode Detection Platform (Molecular Devices, San Jose, CA, USA). The assays were performed in 4 parallels. The $\mathrm{IC}_{50}$ values were calculated using the online tool freely provided by AAT Bioquest-IC50 Calculator.

\section{Conclusions}

This work describes the biological evaluation of 15 novel selenoesters as antibacterials that have a phenyl ring, with different substituents linked to the carbonyl and a functionalized alkyl chain linked to the selenium atom. Eight selenoesters (K1-K8) contain a ketone group in this chain, whereas the seven remaining (N1-N7) are functionalized by a cyano group. The ketone-selenoesters exerted a potent antibacterial activity against the three strains of $S$. aureus considered herein (one sensitive and two MRSA), higher than that observed for the cyano-selenoesters. Seven of the ketone derivatives showed submicromolar MIC values on S. aureus MRSA 272123. The antibacterial activity seemed to be reduced by the inclusion of bulky substituents. Regarding the inhibition of efflux pumps, compound N4 was a more potent inhibitor than the reference reserpine in S. aureus MRSA 43300, and $\mathrm{K} 7$ was a more potent inhibitor than the reference CCCP in S. Typhimurium SE39 $\triangle$ tolC. Furthermore, the substitution with tert-butyl or trifluoromethyl groups seemed to enhance the inhibition of efflux pumps. Different compounds inhibited selectively the two main types of quorum sensing (QS)-K1, $\mathbf{K} 2, \mathbf{K} 8$, and N2 inhibited the AI-1 communication, whereas K2, K4, K7, N3, and N7 inhibited the AI-2 communication. Generally, ketone-selenoesters were better inhibitors of AI-1 and cyano-selenoesters were better inhibitors of AI-2. Finally, all compounds were able to prevent biofilm formation at concentrations below $4 \mu \mathrm{M}$ in both S. aureus ATCC 25923 and P. aeruginosa CCM 3955. At the same time, all compounds disrupted biofilms produced by $S$. aureus at concentrations below $50 \mu \mathrm{M}$, and P. aeruginosa biofilms at concentrations below $25 \mu \mathrm{M}$. All these observations highlight the promising antibacterial, efflux pump inhibitory, quorum sensing inhibitory, and anti-biofilm activity of these novel ketone- and cyano-selenocompounds. 
Author Contributions: G.S. and E.D.-Á. conceived and designed the study. E.D.-Á., N.S.-J., and C.S.-H. synthesized the selenocompounds used in the study. N.S., A.K., K.R., and L.H. performed the laboratory work. G.S., E.D.-Á., and J.V. wrote the article. All authors have read and agreed to the published version of the manuscript.

Funding: The study was supported by the projects SZTE ÁOK-KKA 2018/270-62-2 of the University of Szeged, Faculty of Medicine and GINOP-2.3.2-15-2016-00038 (Hungary); Consejo Superior de Investigaciones Científicas (CSIC, Spain, project LINKA20285); and Czech Ministry of Education, Youth and Sports INTER-COST LTC19007, COST Action CA17104 STRATAGEM.

Acknowledgments: The authors thank Jessica Blair (Institute of Microbiology and Infection, College of Medical and Dental Sciences, University of Birmingham, Birmingham B15 2TT, UK) for providing the Salmonella strains.

Conflicts of Interest: The authors declare no conflict of interest. The funders had no role in the design of the study; in the collection, analyses, or interpretation of data; in the writing of the manuscript; or in the decision to publish the results.

\section{References}

1. Ventola, C.L. The antibiotic resistance crisis: part 1: Causes and threats. P T Peer-Rev. J. Formul. Manag. 2015, 40, 277.

2. Bragg, R.R.; Meyburgh, C.M.; Lee, J.-Y.; Coetzee, M. Potential Treatment Options in a Post-antibiotic Era. Adv. Exp. Med. Biol. 2018, 1052, 51-61. [CrossRef] [PubMed]

3. Coyne, L.A.; Latham, S.M.; Dawson, S.; Donald, I.J.; Pearson, R.B.; Smith, R.F.; Williams, N.J.; Pinchbeck, G.L. Exploring Perspectives on Antimicrobial Use in Livestock: A Mixed-Methods Study of UK Pig Farmers. Front. Vet. Sci. 2019, 6, 257. [CrossRef]

4. Dong, L.T.; Espinoza, H.V.; Espinoza, J.L. Emerging superbugs: The threat of Carbapenem Resistant Enterobacteriaceae. AIMS Microbiol. 2020, 7, 176-182. [CrossRef] [PubMed]

5. El-Hamid, M.I.A.; El-Naenaeey, E.-S.Y.; Kandeel, T.M.; Hegazy, W.A.H.; Mosbah, R.A.; Nassar, M.S.; Bakhrebah, M.A.; Abdulaal, W.H.; Alhakamy, N.A.; Bendary, M.M. Promising Antibiofilm Agents: Recent Breakthrough against Biofilm Producing Methicillin-Resistant Staphylococcus aureus. Antibiot 2020, 9, 667. [CrossRef]

6. Singh, S.; Singh, S.K.; Chowdhury, I.; Singh, R. Understanding the Mechanism of Bacterial Biofilms Resistance to Antimicrobial Agents. Open Microbiol. J. 2017, 11, 53-62. [CrossRef] [PubMed]

7. Costerton, J.W.; Stewart, P.S.; Greenberg, E.P. Bacterial Biofilms: A Common Cause of Persistent Infections. Science 1999, 284, 1318-1322. [CrossRef]

8. Davey, M.E.; O’Toole, G.A. Microbial Biofilms: from Ecology to Molecular Genetics. Microbiol. Mol. Biol. Rev. 2000, 64, 847-867. [CrossRef]

9. Li, Y.-H.; Tian, X. Quorum Sensing and Bacterial Social Interactions in Biofilms. Sensors 2012, 12, $2519-2538$. [CrossRef]

10. Miller, M.B.; Bassler, B.L. Quorum Sensing in Bacteria. Annu. Rev. Microbiol. 2001, 55, 165-199. [CrossRef]

11. Alcalde-Rico, M.; Hernando-Amado, S.; Blanco, P.; Martínez, J. Multidrug Efflux Pumps at the Crossroad between Antibiotic Resistance and Bacterial Virulence. Front. Microbiol. 2016, 7, 1483. [CrossRef] [PubMed]

12. Yazhiniprabha, M.; Vaseeharan, B. In vitro and in vivo toxicity assessment of selenium nanoparticles with significant larvicidal and bacteriostatic properties. Mater. Sci. Eng. C 2019, 103, 109763. [CrossRef] [PubMed]

13. Cihalova, K.; Chudobova, D.; Michalek, P.; Moulick, A.; Guran, R.; Kopel, P.; Adam, V.; Kizek, R. Staphylococcus aureus and MRSA Growth and Biofilm Formation after Treatment with Antibiotics and SeNPs. Int. J. Mol. Sci. 2015, 16, 24656-24672. [CrossRef] [PubMed]

14. Jastrzebska, I.; Mellea, S.; Salerno, V.; Grzes, P.A.; Siergiejczyk, L.; Niemirowicz-Laskowska, K.; Bucki, R.; Monti, B.; Santi, C.; Laskowska, N.-. PhSeZnCl in the Synthesis of Steroidal $\beta$-Hydroxy-Phenylselenides Having Antibacterial Activity. Int. J. Mol. Sci. 2019, 20, 2121. [CrossRef] [PubMed]

15. Ngo, H.X.; Shrestha, S.K.; Green, K.D.; Garneau-Tsodikova, S. Development of ebsulfur analogues as potent antibacterials against methicillin-resistant Staphylococcus aureus. Bioorganic Med. Chem. 2016, 24, 6298-6306. [CrossRef]

16. Gajdács, M.; Spengler, G.; Sanmartín, C.; Marć, M.A.; Handzlik, J.; Domínguez-Álvarez, E. Selenoesters and selenoanhydrides as novel multidrug resistance reversing agents: A confirmation study in a colon cancer MDR cell line. Bioorganic Med. Chem. Lett. 2017, 27, 797-802. [CrossRef] [PubMed] 
17. Kharma, A.; Misak, A.; Grman, M.; Brezova, V.; Kurakova, L.; Barath, P.; Jacob, C.; Chovanec, M.; Ondrias, K.; Domínguez-Álvarez, E. Release of reactive selenium species from phthalic selenoanhydride in the presence of hydrogen sulfide and glutathione with implications for cancer research. New J. Chem. 2019, 43, 11771-11783. [CrossRef]

18. Reich, H.J.; Hondal, R.J. Why Nature Chose Selenium. ACS Chem. Biol. 2016, 11, 821-841. [CrossRef]

19. Fernandez-Lazaro, D.; Fernandez-Lazaro, C.I.; Mielgo-Ayuso, J.; Navascués, L.J.; Córdova, A.; Seco-Calvo, J. The Role of Selenium Mineral Trace Element in Exercise: Antioxidant Defense System, Muscle Performance, Hormone Response, and Athletic Performance. A Systematic Review. Nutrients 2020, 12, 1790. [CrossRef]

20. Stolwijk, J.M.; Garje, R.; Sieren, J.C.; Buettner, G.R.; Zakharia, Y. Understanding the Redox Biology of Selenium in the Search of Targeted Cancer Therapies. Antioxidants 2020, 9, 420. [CrossRef]

21. Sumner, S.E.; Markley, R.L.; Kirimanjeswara, G.S. Role of Selenoproteins in Bacterial Pathogenesis. Biol. Trace Element Res. 2019, 192, 69-82. [CrossRef] [PubMed]

22. Rayman, M.P. The importance of selenium to human health. Lancet 2000, 356, 233-241. [CrossRef]

23. Mosolygó, T.; Kincses, A.; Mosolygó, T.; Marć, M.A.; Nové, M.; Gajdács, M.; Sanmartín, C.; McNeil, H.E.; Blair, J.M.A.; Domínguez-Álvarez, E. Antiviral, Antimicrobial and Antibiofilm Activity of Selenoesters and Selenoanhydrides. Molecules 2019, 24, 4264. [CrossRef]

24. Nové, M.; Kincses, A.; Szalontai, B.; Rácz, B.; Blair, J.M.A.; González-Prádena, A.; Benito-Lama, M.; Domínguez-Álvarez, E.; Spengler, G. Biofilm Eradication by Symmetrical Selenoesters for Food-Borne Pathogens. Microorganisms 2020, 8, 566. [CrossRef]

25. Mosolygó, T.; Kincses, A.; Csonka, A.; Tönki, Á.S.; Witek, K.; Sanmartín, C.; Marć, M.A.; Handzlik, J.; Kieć-Kononowicz, K.; Domínguez-Álvarez, E.; et al. Selenocompounds as Novel Antibacterial Agents and Bacterial Efflux Pump Inhibitors. Molecules 2019, 24, 1487. [CrossRef]

26. Peña-Morán, O.A.; Villarreal, M.L.; Alvarez, L.; Meneses-Acosta, A.; Rodríguez-López, V. Cytotoxicity, Post-Treatment Recovery, and Selectivity Analysis of Naturally Occurring Podophyllotoxins from Bursera fagaroides var. fagaroides on Breast Cancer Cell Lines. Molecules 2016, 21, 1013. [CrossRef]

27. Spengler, G.; Kincses, A.; Gajdács, M.; Amaral, L. New Roads Leading to Old Destinations: Efflux Pumps as Targets to Reverse Multidrug Resistance in Bacteria. Molecules 2017, 22, 468. [CrossRef]

28. Yong, Y.-C.; Zhong, J.-J. Impacts of Quorum Sensing on Microbial Metabolism and Human Health. In Future Trends in Biotechnology; Zhong, J.-J., Ed.; Springer: Berlin/Heidelberg, Germany, 2012; Volume 131, pp. $25-61$. [CrossRef]

29. Chatterjee, R.; Shreenivas, M.M.; Sunil, R.; Chakravortty, D. Enteropathogens: Tuning Their Gene Expression for Hassle-Free Survival. Front. Microbiol. 2019, 9, 3303. [CrossRef]

30. Gibbons, S.; Oluwatuyi, M.; Kaatz, G.W. A novel inhibitor of multidrug efflux pumps in Staphylococcus aureus. J. Antimicrob. Chemother. 2003, 51, 13-17. [CrossRef]

31. Rezzonico, F.; Smits, T.H.M.; Duffy, B. Detection of AI-2 Receptors in Genomes of Enterobacteriaceae Suggests a Role of Type-2 Quorum Sensing in Closed Ecosystems. Sensors 2012, 12, 6645-6665. [CrossRef]

32. Taga, M.E.; Semmelhack, J.L.; Bassler, B.L. The LuxS-dependent autoinducer AI-2 controls the expression of an ABC transporter that functions in AI-2 uptake in Salmonella typhimurium. Mol. Microbiol. 2008, 42, 777-793. [CrossRef] [PubMed]

33. Domínguez Álvarez, E.; Spengler, G.; Jacob, C.; Sanmartín Grijalba, M.C. Selenoester-Containing Compounds for Use in the Treatment of Microbial Infections or Colorectal Cancer. European Patent EP18382693, 28 September 2018.

34. Christopher, P.J.; Polgar, E.P. (Eds.) Methods for Dilution Antimicrobial Susceptibility Tests for Bacteria That Grow Aerobically, 11th ed.; Clinical and Laboratory Standards Institute: Wayne, MI, USA, 2018.

35. Viktorova, J.; Stupák, M.; Rehorova, K.; Dobiasova, S.; Hoang, L.; Hajslova, J.; Van Thanh, T.; Van Tri, L.; Van Tuan, N.; Ruml, T. Lemon Grass Essential Oil does not Modulate Cancer Cells Multidrug Resistance by Citral-Its Dominant and Strongly Antimicrobial Compound. Foods 2020, 9, 585. [CrossRef] [PubMed]

36. Hoang, L.; Beneš, F.; Fenclova, M.; Kronusova, O.; Švarcová, V.; Rehorova, K.; Švecová, E.B.; Vosátka, M.; Hajslova, J.; Kaštánek, P.; et al. Phytochemical Composition and In Vitro Biological Activity of Iris spp. (Iridaceae): A New Source of Bioactive Constituents for the Inhibition of Oral Bacterial Biofilms. Antibiot 2020, 9, 403. [CrossRef] [PubMed] 
37. Sandberg, M.E.; Schellmann, D.; Brunhofer, G.; Erker, T.; Busygin, I.; Leino, R.; Vuorela, P.; Fallarero, A. Pros and cons of using resazurin staining for quantification of viable Staphylococcus aureus biofilms in a screening assay. J. Microbiol. Methods 2009, 78, 104-106. [CrossRef] [PubMed]

38. Haney, E.F.; Trimble, M.J.; Cheng, J.T.; Vallé, Q.; Hancock, R.E.W. Critical Assessment of Methods to Quantify Biofilm Growth and Evaluate Antibiofilm Activity of Host Defence Peptides. Biomolecules 2018, 8, 29. [CrossRef]

Publisher's Note: MDPI stays neutral with regard to jurisdictional claims in published maps and institutional affiliations.

(C) 2020 by the authors. Licensee MDPI, Basel, Switzerland. This article is an open access article distributed under the terms and conditions of the Creative Commons Attribution (CC BY) license (http://creativecommons.org/licenses/by/4.0/). 